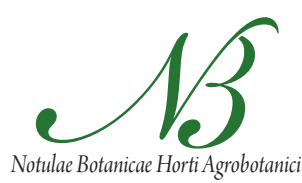

Cluj-Napoca

\title{
A Preliminarily Phylogeny Study of the Eriobotrya Based on the nrDNA $A d b$ Sequences
}

\author{
Yang XINAGHUI' ${ }^{1}$, Li PING ${ }^{1,2 *}$, Zhang ZHIKE ${ }^{1}$, Lin \\ SHUNQUAN ${ }^{1 * *}, \mathrm{Hu}_{\text {GUIBIN }}{ }^{1}$, He XIAOLONG \\ ${ }^{1}$ South China Agricultural University, College of Horticulture, Guangzhou, Guangdong 510642, \\ China; loquat@scau.edu.cn ( ${ }^{*}$ co-first authors, ${ }^{*}$ corresponding author) \\ ${ }^{2}$ Foshan Supervises and Tests Center for Quality and Safety of Primary Products, Foshan, Guangdong 528000, China
}

\begin{abstract}
Phylogenetic relationships of the genus Eriobotrya Lindl. were examined based on the nrDNA $A d h$ sequences. A phylogenetic tree of 14 loquat accessions (species, varieties and forma) was generated by using Photinieae serrulaia L. as an outgroup and Rhaphiolepis indica (L.) Lindl. as an ingroup, which represent the two closest genera of Eriobotyra. The results showed that these loquat accessions were divided into two main clades in the consensus tree. Clade I included E. seguinii Card and group A formed by E. henryi Nakai, E.bengalensis Hook.f., and forma angustifolia Vidal. Clade II is composed of the other taxas which included three groups. E. cavaleriei Rehd and E. fragrans Champ formed group B; group C consisted of E. prinoides Rehd. \& Wils. var. dadunensis H.Z.Zhang, and E. japonica Lindl.; and group D included E. deflexa Nakai and E. deflexa Nakai Var.buisanensis NaKai. Since E. deflexa Nakai, E. deflexa Nakai Var.buisanensis NaKai and E. kwangsiensis Chun, were closer in the phylogenetic tree; while E. prinoides Rehd. \& Wils. var. dadunensis H.Z.Zhang, E. japonica Lindl, E. prinoides Rehd \& Wils and E.elliptica Lindl. were close with each other, they may be locataed at a similar place of the phylogenetic stage. However, E. malipoensis Kuan need further studies on its phylogenetis relationship for it was separated from the others. Results further support the theory that E. cavaleriei Rehd could be a variety of E. fragrans Champ.
\end{abstract}

Keywords: Adh gene, Eriobotrya, loquat, phylogenesis

\section{Introduction}

Eriobotrya Lindl. belongs to the family Rosaceae, subfamily Maloideae (Lindley, 1822). The genus Eriobotrya Lindl. comprises 21 species including varieties and forms, with Yunnan Province in China the centre of diversity (Yang, 2005; Yang et al., 2005). Further research on the origin and evolution of Eriobotrya is important to establish a solid foundation to achieve improvement of cultivated species such as loquat (Eriobotrya japonica Lindl.) and to further exploit species of Eriobotrya plants for industrial and pharmaceutical purposes.

In previous studies, the interspecific relationship, origin and evolutionary development of Eriobotrya were studied by morphology and molecular markers (Cheng et al., 2003; Vilanova et al., 2001). Li et al. investigated the molecular phylogeny of Eriobotrya by ITS sequence and suggested that the taxonomic treatment of E. cavaleriei Rehd as a variety of $E$. fragrans $\mathrm{Champ}(\mathrm{Li}$ et al., 2009). However, results from different studies were not always consistent.

Previous studies have demonstrated that fast evolving introns of low-copy nuclear genes could provide more essential phylogenetic information than chloroplast or nu- clear genes to better define interspecific relationships. In addition, $A d h$ gene structure is a useful tool for improving the robustness of phylogenetic reconstruction at all taxonomic levels (Small and Wendel, 2000). Moreover, $A d b$ is also an acetaldehyde-metabolic related gene and exists in both animals and plant. Thus, the $A d h$ gene was selected to study the relationship and evolution of Eriobotrya.

\section{Materials and methods}

Sixteen accessions were selected as experimental materials, including 14 Eriobotrya and two relative genera. All of them were preserved ex situ for the future research in the Loquat Germplasm Repository of Horticultural College, South China Agricultural University, P. R. China. The details of these materials, including their original locations are presented in Tab. 1.

Studies of Campbell et al. (1995; 2007) showed that Eriobotrya was close to other Maloideae species including Rhaphiolepis indica (L.) Lindl., Osteomeles anthyllidifolia Lindl., Sorbus scopulina Hedl., Malus prunifolia (Willd.) Barkh, Pyruspyrifolia (Burm.) Nakai. In this study Rhaphiolepis indica was designated as an ingroup while Photinieae serrulata L. was designated as an outgroup. 
Tab. 1. Some information of the materials

\begin{tabular}{|c|c|c|c|}
\hline Code & Taxon & Original location & Voucher \\
\hline 1 & E.elliptica Lindl. & Daweishan, Yunnan & (S.Q.Lin) Ee4 \\
\hline 2 & E. prinoides Rehd \& Wils. & Shiping, Yunnan & \\
\hline 3 & E. deflexa Nakai & Fenghuangshan, Guangdong & (S.Q.Lin) Ed2 \\
\hline 4 & E. deflexa Nakai var.buisanensis Nakai & Henchun, Taiwan & (S.Q.Lin) Edk1 \\
\hline 5 & E. malipoensis Kuan & Malipo, Yunnan & (S.Q.Lin) Em 1 \\
\hline 6 & E. henryi Nakai & Chengjiang, Yunnan & (S.Q.Lin) Eh1 \\
\hline 7 & Photinieae serrulata L.* & Guilin, Guangxi & (S.Q.Lin) Ps1 \\
\hline 8 & E. japonica Lindl. & Nanling, Guangdong & (S.Q.Lin) Ej1 \\
\hline 9 & E. kwangsiensis Chun & Dayaoshan, Guangxi & (S.Q.Lin) Ek3 \\
\hline 10 & E. prinoides Rehd. \& Wils. var. dadunensis H.Z.Zhang & Hanyuan, Sichuan & (S.Q.Lin) Ed1 \\
\hline 11 & E.bengalensis Hook.f. & Gaoli-Gongshan, Yunnan & (S.Q.Lin) Eb2 \\
\hline 12 & forma angustifolia Vidal & Kunming, Yunnan & (S.Q.Lin) Eba1 \\
\hline 13 & E. fragrans Champ & Nanling, Guangdong & (S.Q.Lin) Ef1 \\
\hline 14 & E. cavaleriei Rehd & Nanling, Guangdong & (S.Q.Lin) Ec1 \\
\hline 15 & E. seguinii Card & Lingle, Guangxi & (S.Q.Lin) Ese1 \\
\hline 16 & Rhaphiolepis indica(L.) Lindl. ** & Xinyi, Guangdong & (S.Q.Lin) Ri1 \\
\hline
\end{tabular}

*outgroup; ${ }^{* *}$ ingroup

Genomic DNAs were isolated from leaf tissue by a modified method (Liu et al., 2005) according to Doyle and Doyle (1987). PCR amplification by MJ Research thermocyclers, were carried out with $A d b \mathrm{~F} 2$ and $A d b \mathrm{R} 2$ primers (Lin et al., 2004) in a $50 \mu \mathrm{L}$ reaction volume including 2.5 unit Taq polymerase (Promega), $10 \times \mathrm{PCR}$ buffer (Promega), $200 \mu \mathrm{M}$ each dNTP, $2.0 \mathrm{mM} \mathrm{MgCl}, 10$ pmol each primer, and $2 \mu \mathrm{L}$ template DNA (ca. 10-100 ng).

PCR programs were performed with the following temperature profile: a pre-denaturation step of $4 \mathrm{~min}$ at $94^{\circ} \mathrm{C}$ followed by 5 cycles of denaturation $1 \mathrm{~min}$ at $94^{\circ} \mathrm{C}$, an annealing at $56^{\circ} \mathrm{C}$ for $45 \mathrm{sec}$, and an extension at $72^{\circ} \mathrm{C}$ for $1.5 \mathrm{~min}$, and then followed by 30 cycles of a denaturation at $94^{\circ} \mathrm{C}$ for $20 \mathrm{sec}$, an annealing at $55^{\circ} \mathrm{C}$ for $20 \mathrm{sec}$, and an extension at $72^{\circ} \mathrm{C}$ for $1.5 \mathrm{~min}$, with a final extension for 10 min at $72^{\circ} \mathrm{C}$.

The 1300bp specific $A d h$ sequences were obtained by using $A d b \mathrm{~F} 2$ and $A d b \mathrm{R} 2$ primers and these PCR products were purified and cloned into the Easy Vector of PGEM ${ }^{\circledR}{ }_{-}$ TSystem II (Promega) according to the manufacturer's instructions, and then transferred into E. coli TOP10. The recombinant plasmids were obtained after screened by the blue-white method and identified by restriction endonuclease analysis and PCR.

Individual $A d h$-containing plasmids were isolated and sequenced on an ABI Prism automated DNA sequencer at Shanghai Invitrogen biotechnology Co., Ltd.. Then these sequences were compared with the corresponding DNA sequences of other species reported in GenBank by BLAST software, and finally, the nucleotide homology was found.

The DNA sequences obtained were edited, aligned with ClustalX software (Thompson et al., 1997) and adjusted manually where necessary. Phylogenetic analyses by
PAUP4.0b10 (Swofford, 2003), and the construction of the maximum-parsimony (MP) were performed with the heuristic search.

In phylogenetic analysis, ambiguous sites were excluded from the matrix. Gaps were treated as missing information while the inferred indels of clear alignment were recorded as unordered separated characters. All clear characters and character-state transformations were given an equal weight.

A heuristic search was performed for each data set, with RANDOM stepwise data addition (1000 replications with a start seed of 1) and TBR branch-swapping algorithm options. To assess the relative support for each clade, bootstrap values were calculated from 1000 replicate analyses with the heuristic search strategy and simple addition sequence of the taxa. The amount of phylogenetic information in the MP analysis was constructed with the consistency index (CI) and retention index (RI). Maximum parsimony trees were constructed using PAUP4.0b10 program (Swofford, 2003). Cladistic analysis of the phylogenetic relationship was conducted by using Wagner parsimony and applying heuristic search with tree bisection reconnection (TBS) branch-swapping and simple stepwise taxon application of 1000 replications.

\section{Results}

Specific primer polymerase chain reaction on Adh gene of Eriobotyra Lindl

Fourteen Eriobotrya plants and two relatives were amplified with the universal primers, $A d b \mathrm{~F} 2$ and $A d b \mathrm{R} 2$, and the $1300 \mathrm{bp}$ specific amplified strands were clearly visualized. Fig. 1 shows the result of PCR amplification. 


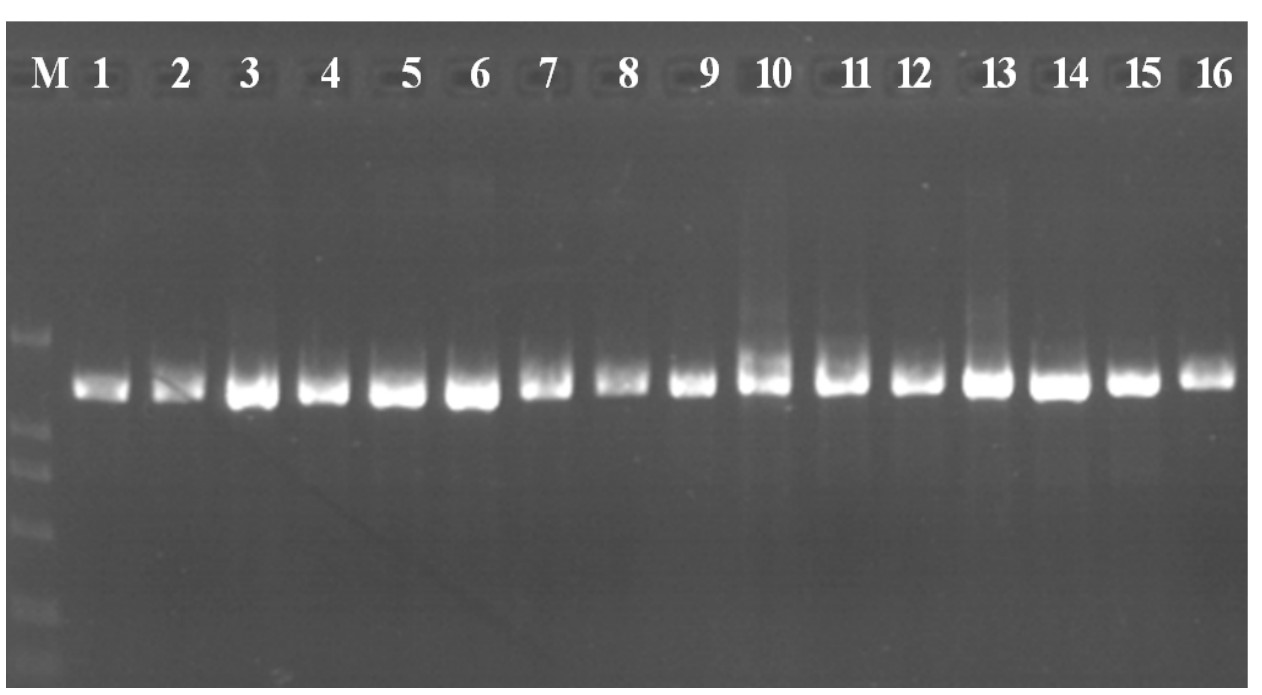

Fig. 1. Products of PCR amplified on Adh gene of samples on 14 Eriobotrya and outgroup of Rhaphiolepis indica. and ingroup of Photinieae serrulaia From left to right: M: DL2000; 1. E. elliptica; 2. E. prinoides; 3. E. deflexa; 4. E. deflexa var. buisanensis; 5. E. malipoensis; 6. E. henryi; 7. Photinieae serrulaia; 8. E. japonica; 9. E. kwangsiensis; 10. E. prinoides var. dadunensis; 11. E.bengalensis; 12. E. bengalensis forma angustifolia; 13. E. fragrans; 14. E. cavaleriei; 15. E. seguini; 16. Rhaphiolepis indica

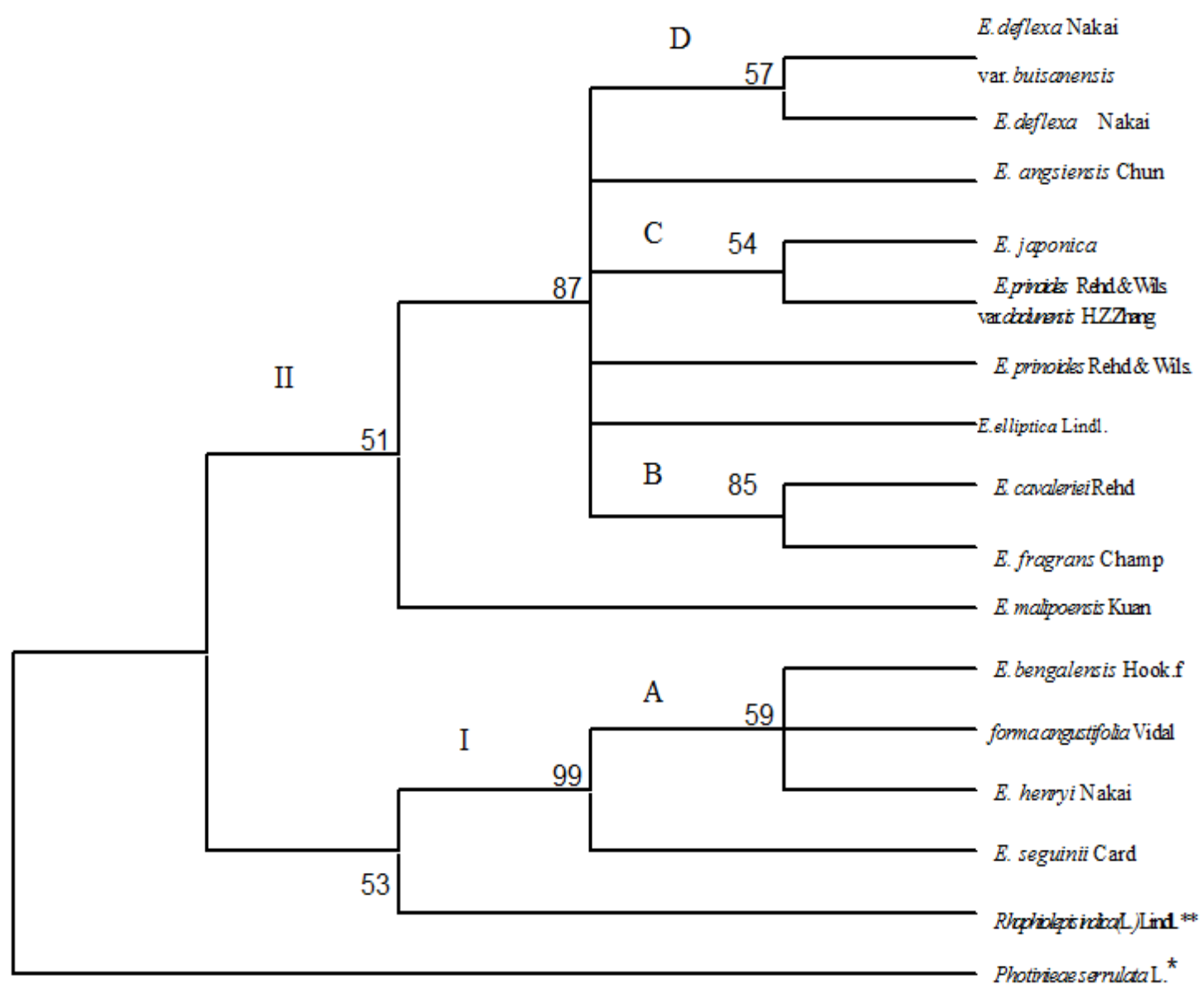

Fig. 2. Majority-rule consensus trees based on $A d h$ sequences (Tree length=1001, Consistency index $=0.9371$ ), Retention index $=0.9709$ ). Numbers in the branches are bootstrap percentages above $50 \%$ and by 1000 replications; indicate outgroup; ${ }^{* *}$ indicate ingroup 
236

Phylogenetic analysis of Eriobotrya plants base on Adh gene

Sequencing analysis showed that after arrangement, the matrix is $1332 \mathrm{bp}$ long. The $469 \mathrm{bp}$ were the conserved motifs and 727 bp were the informative polymorphic sites. This result means that the $A d h$ gene sequence have high genetic diversity in Eriobotrya.

The phylogenetic tree based on the sequence of 14 Eriobotrya plants with Rhaphiolepis indica as the ingroup and Photinieae serrulata as outgroup was constructed by the MP method. The phylogenetic tree had 1001 steps, with a consistency index (CI) 0.9371 and a retention index (RI) 0.9709 . Fig. 2 shows the majority-rule consensus trees. The result shows the phylogenic tree could be divided into two clades. E. henryi, E.bengalensis and E.bengalensis forma angustifolia clustered into Group A (Bootstrap value $=59 \%)$, and then join together with E. seguinii for Clade I (Bootstrap Value $=99 \%)$. All the rest clustered into the Clade II. There are four groups in the Clade II, including Group B with $E$. cavaleriei and $E$. fragrans (Bootstrap value $=85 \%$ ), Group $\mathrm{C}$ with E. prinoides. var. dadunensis and E. japonica (Bootstrap value $=54 \%$ ), Group D with $E$. deflexa and $E$. deflexa var.buisanensis (Bootstrap value $=57 \%)$. E. henryi has the closest relation with the outgroup Photinieae serrulaia in Clade I. In Clade II, E.elliptica, E. prinoides, and E. angsiensis formed monophyletic group, respectively, while E.malipoensis was at the base of Clade II (Bootstrap Value $=51 \%)$. Therefore, the interspecies relationships and the phylogeny positions of Eriobotyra require further investigation.

\section{Discussion}

$A d h$ gene sequences can be used for systematic analysis, suitable for studies on phylogeny relationships and interfamily or intergeneric classification. In China, the $A d h$ gene sequence was used to study the phylogenetic and genetic relationships among some plants such as Paeonia Section Moutan DC. (Lin et al., 2004), Oryza (Ge et al., 1999), Gossypium (Small et al., 1998). The results show that when using universal primers, a single $A d h$ gene band was obtained for Eriobotrya species, which provide favorable conditions to evaluate phylogeny.

The phylogenetic MP tree of 14 Eriobotrya plants with Photinieae serrulaia as an outgroup and Rhaphiolepis indica as an ingroup, was constructed by $A d h$ gene sequence analysis. We draw the following conclusions: the phylogenetic tree could be divided into two clades. E. henryi, $E$. bengalensis, and $E$. bengalensis forma angustifolia clustered into Group A, and then join together with E. seguinii into Clade I while the rest clustered into Clade II. There are four groups in Clade II, including Group B with E. cavaleriei and E. fragrans, Group C group with E. prinoides. var. dadunensis and E. japonica., Group D with E. deflexa and E. deflexa var. buisanensis, which is largely consistent with the result analyzed by ITS sequence(Li et al., 2009).
The relastionships among E. kwangsiensis, E. deflexa, and E. deflexa var. buisanensis were so close that showed they may have the same ancestor, which agrees with the previous study of Yang (2005). Since E. deflexa, E. deflexa var. buisanensis and $E$. kwangsiensis were closer in the phylogenetic tree; while E. prinoides var. dadunensis, E. japonica, E. prinoides and E. elliptica were close with each other, they may lain at the similar place of the phylogenetic stage, respectively. However, E. malipoensis need further studies on its phylogenetic relationship for it was separated from others.

In the phylogenetic tree, E. cavaleriei and E. fragrans were clustered together and formed Group B group with high bootstrap value $(85 \%)$ which indicated a relatively close relationship. The results agree with the viewpoint that E. cavaleriei could be treated as a variety under $E$. fragrans Champ. However, the bootstrap value of some groups are not very high $(<60 \%)$, which means that to clarify the exact relationships among Eriobotrya plants, a more intensive study with more evidence should be carried out.

Small and Wendel (2000) believed that the low resolution of subsection Erioxylum, gene tree $A d h A$ in Gossypium. was caused by both gene flow and unrecognized paralogy and linkage sorting of the $A d h A$ gene. Sang et al. (2002) also thought that lineage sorting, unrecognized paralogy and gene transformation may cause the low resolution of $A d h$ gene tree in Paeonia. From the above analysis, we conclude that although the $A d h$ gene sequence holds a high genetic diversity in Eriobotrya, some species still cannot separated. It can be suggested that the molecular evolution research of Eriobotrya genus is still at an initial phase. A deeper study is required to to determine if there are gene exchanges and unrecognized paralogies.

\section{Acknowledgement}

This work was supported by the National Natural Science Foundation of China (No. 30971836) and Key Laboratory of Innovation and Utilization for Germplasm Resources in Horticultural Crops in Southern China of Guangdong Higher Education Institutes, South China Agricultural University, and our sincere thanks go to Prof. Jules Janick for language correction and constructive comments on the manuscript preparation.

\section{References}

Cheng YT, Zhong ZX, Guo ZX, Guo YQ, Cai YQ, Chen JY, Lu XM, Wu JS(2003). RAPD analysis of main species and cultivars in Eriobotrya. Acta Agric Univ Jiangxiensis. Natural Sci 25(2):259-261.

Doyle JJ, Doyle JL (1987). A rapid isolation procedure for small quantities of fresh leaf tissue. Phytochem Bul 19:11-15.

Ge S, Sang T, Lu BR, Hong DY (1999). Phylogeny of rice genomes with emphasis on origins of allotetraploid species. Proc National Acad Sci (USA) 96(25):14400-14405

Li P, Lin SQ, Yang XH, Hu G.B, Jang YM (2009). Molecular 
Phylogeny of Eriobotrya Lindl.(Loquat) Inferred from Internal Transcribed Spacer sequences of Nuclear Ribosome. Pak J Bot 41(1):185-193

Lindley J (1822). Description as E.japonica. Trans Linn Soc 8:102.

Lin QB, Zhou ZQ, Zhao X, Pan KY, Hong DY (2004). Interspecific relationships among the wild species of Paeonia Sect. Moutan D C. based on DNA sequences of $A d h$ Gene Family. Acta Hort Sinica 31(5) 627-632.

Liu YX, Yang XH, Lin SQ, Hu GB, Liu CM (2005). An improved procedure for nuclear DNA isolation from Eriobotrya plants and its application. J Fruit Sci 22:182-185.

Sang T (2002). Utility of low-copy nuclear gene sequences in plant phylogentics. Crit Rev Biochem Molec Biol 37(3):121-147

Small RL, Ryburn JA, Cronn RC, Seelanan T, Wendel JF (1998). The tortoise and the hare: choosing between noncoding plastome and nuclear $A d h$ sequences for phylogeny reconstruction in a recently diverged plant group. Amer J Bot 85:1301-1315.

Small RL, Wendel JF (2000). Phylogeny, Duplication, and IntraspecificVariation of $A d h$ Sequences in New World diploid Cottons (Gossypium L. Malvaceae). Molecular Phylogenetics and Evolution 16(1):73-84
Swofford DL (2003). PAUP. Phylogenetic Analysis Using Parsimony and Other Methods. Version 4.0b10. Sunderland, Massachusetts: Sinauer Associates.

Thompson JD, Gibson TJ, Plewinak F, Jeanmougin F, Higgins DG (1997). The Clustal X windows interface: flexible strategies for multiple sequence alignment aided by quality analysis tools. Nucleic Acids Res 25:4876-4882.

Vilanova S, Badenes M L, Marinez-Calvo J (2001). Analysis of loquat (Eriobotrya japonica Lindl) germplasm by RAPD molecular markers. Euphytica 121:25-29

Yang XH (2005). A systematic study of the genus Eriobotrya. Doctoral dissertation of South China Agric Univ 1-99 p.

Yang XH, Glakpe K, Lin SQ, Hu YL, He YH, Nguyen TCN, Liu YX, Hu GB, Liu CM (2005). Taxa of plants of genus Eriobotrya around the world and native to Southeastern Asia. J Fruit Sci 22: 55-59. 